\title{
Assessment of the Effect of Visual Impairment on Mortality through Multiple Health Pathways: Structural Equation Modeling
}

\author{
Sharon L. Christ, ${ }^{1}$ David J. Lee, ${ }^{2,3}$ Byron L. Lam, ${ }^{3}$ D. Diane Zheng, ${ }^{2}$ and \\ Kristopher L. Arbeart ${ }^{2}$
}

Purpose. To estimate the direct effects of self-reported visual impairment (VI) on health, disability, and mortality and to estimate the indirect effects of VI on mortality through health and disability mediators.

Methods. The National Health Interview Survey (NHIS) is a population-based annual survey designed to be representative of the U.S. civilian noninstitutionalized population. The National Death Index of 135,581 NHIS adult participants, 18 years of age and older, from 1986 to 1996 provided the mortality linkage through 2002. A generalized linear structural equation model (GSEM) with latent variable was used to estimate the results of a system of equations with various outcomes. Standard errors and test statistics were corrected for weighting, clustering, and stratification.

Results. VI affects mortality, when direct adjustment was made for the covariates. Severe VI increases the hazard rate by a factor of 1.28 (95\% CI: 1.07-1.53) compared with no VI, and some VI increases the hazard by a factor of 1.13 ( $95 \%$ CI: 1.07-1.20). VI also affects mortality indirectly through selfrated health and disability. The total effects (direct effects plus mediated effects) on the hazard of mortality of severe VI and some VI relative to no VI are hazard ratio (HR) 1.54 (95\% CI: 1.28-1.86) and HR 1.23 (95\% CI: 1.16-1.31), respectively.

Conclusions. In addition to the direct link between VI and mortality, the effects of VI on general health and disability contribute to an increased risk of death. Ignoring the latter may lead to an underestimation of the substantive impact of VI on mortality. (Invest Ophthalmol Vis Sci. 2008;49:3318-3323) DOI: $10.1167 /$ iovs.08-1676

V isual impairment (VI) is associated with a wide range of adverse physical and psychological outcomes. Verbrugge et al. ${ }^{1}$ examined the prevalence and consequences of 15 chronic conditions, reporting that self-reported VI is the third most disabling condition, ranked only behind cerebrovascular disease and hip fracture. Poor vision in older adults has a greater impact on overall mental health than does stroke and

From the ${ }^{1}$ Odum Institute, University of North Carolina, Chapel Hill, North Carolina; and the ${ }^{2}$ Department of Epidemiology and Public Health, and the ${ }^{3}$ Bascom Palmer Eye Institute, University of Miami School of Medicine, Miami, Florida.

Supported by Grant R03-EY016481 from the National Eye Institute and Grant R01-OH03915 from the National Institute of Occupational Safety and Health.

Submitted for publication January 2, 2008; revised March 7, 2008; accepted June 4, 2008.

Disclosure: S.L. Christ, None; D.J. Lee, None; B.L. Lam, None; D.D. Zheng, None; K.L. Arheart, None

The publication costs of this article were defrayed in part by page charge payment. This article must therefore be marked "advertisement" in accordance with 18 U.S.C. $\$ 1734$ solely to indicate this fact.

Corresponding author: Sharon L. Christ, Odum Institute, 06 Manning Hall, CB \#3355, UNC at Chapel Hill, Chapel Hill, NC 27599-3355; slchrist@email.unc.edu. heart attack. $^{2}$ VI and eye disease are also associated with impaired activities of daily living, ${ }^{3-8}$ social isolation, ${ }^{4,8,9} \mathrm{cog}$ nitive impairment, ${ }^{10}$ depression, ${ }^{11,12}$ reduced quality of life, ${ }^{2,13}$ impaired functional status, ${ }^{14}$ impaired mobility, ${ }^{3}$ increased dependency on others, ${ }^{15,16}$ increased motor vehicle accident risk, ${ }^{17,18}$ risk of falls and fractures, ${ }^{19,20}$ and poor self-rated health. ${ }^{4,21}$ Finally, VI is also associated with reduced survival in numerous population-based surveys. ${ }^{3,5,22-28}$ What is not clear at present is which mechanisms explain the association between VI and mortality. For example, there is a report of an association between severe VI and unintentional injury mortality that is likely to be causally linked. ${ }^{29}$ However, it is less clear what mechanisms explain the association of VI or eye disease with coronary heart disease and cancer mortality. ${ }^{22-26,30,31}$

One challenge faced by investigators studying the relationship between VI and mortality is the selection of covariates, given that VI broadly affects psychosocial functioning. For example, a relationship has been found between VI and selfrated health, ${ }^{5,21,32}$ which in turn has been a predictor of mortality in some studies. ${ }^{33,34}$ The inclusion of self-rated health as a covariate in mortality models may therefore lead to an underestimate of the mortality risk attributable to VI.

The purpose of this study was to examine the direct and indirect (mediated) effects of VI on mortality risk while controlling for the presence of other chronic conditions and other health indicators. Using structural equation modeling and controlling for relevant covariates such as age, sex, and educational attainment, we estimated direct effects on mortality risk and tested the hypotheses that VI has an indirect adverse effect on mortality via self-rated health and disability (see Fig. 1).

\section{Materials ANd Methods}

\section{Study Population and Design}

A nationally representative sample of 135,581 adult respondents from The National Health Interview Survey (NHIS) pooled over the years 1986 to 1996 was analyzed. The NHIS employs a complex sample survey designed to obtain population-based samples that are representative of the U.S. civilian noninstitutionalized population. NHIS participants who were 18 years of age or older were included in the National Death Index (NDI) mortality linkage, which is complete through December 31, 2002. The sample used in this analysis comprised those respondents who provided sufficient demographic information to complete the mortality linkage and who were one of the random one sixth of the total NHIS sample to be selected for the VI module.

\section{Variables}

Participants were asked to indicate whether they were blind in one or both eyes or had any other trouble seeing with one or both eyes, even when wearing glasses. Visual impairment (VI) was subsequently coded as (1) severe VI: blind in both eyes; (2) some VI: VI in both eyes, blind in one eye, visually impaired in the other eye, or blind or visually impaired in one eye only, with the other eye having good vision or not 
mentioned; and (3) no VI: no impairment in either eye. For some respondents, proxy reporters answered the VI questions.

Disability was measured as a latent variable with two indicators: (1) the number of days in bed in the past 2 weeks and (2) the number of reduced-activity days in the past 2 weeks. Self-reported health status was measured on a five-point ordinal scale: (1) excellent, (2) very good, (3) good, (4) fair, and (5) poor.

Covariates include age in years, sex (female reference), threecategory racial identity (white [reference], black, and other races), marital status (not married [reference] and married), education level (less than high school [reference], high school, and more than high school), and the number of nonocular health conditions. Respondents listed their health conditions, which were subsequently classified according to an International Classification of Diseases 9th revision (ICD-9) code based on follow-up questions detailing the conditions. A three-category nonocular health condition variable was then created as follows: no conditions (reference), one condition, and two or more conditions.

\section{Analysis}

Structural equation modeling (SEM) is a general modeling framework that incorporates many common statistical methods, including regression, analysis of variance (ANOVA), confirmatory factor analysis, and simultaneous equations. ${ }^{35}$ SEM has advanced to include the simultaneous estimation of generalized linear equations (GSEM), such as logistic, Poisson, and Cox proportional hazards regression models. ${ }^{36}$ GSEM offers several advantages over traditional analytic methodology. First, as demonstrated in the present analysis, it allows for the estimation of multiple equations simultaneously, so that associations between multiple predictor and outcome variables can be assessed in the same model- even when the distribution of outcome measures varies from dichotomous (e.g., VI), to ordinal (e.g., self-rated health), to Poisson (e.g., disability indicators), to continuous, to time-dependent (e.g., mortality) events. Second, constructs such as disability can be estimated net of random measurement error. Theoretically meaningful constructs can be developed by using latent variables (or factors), which are unobserved variables that are indirectly measured by multiple observed variables through a system of equations. Heuristically, the multiple observed variables are optimally combined into a composite representing the latent variable. This method has great potential for improving the measurement quality of health data collected in surveys, given the ability to adjust for random measurement error. Third, GSEM provides a powerful tool for the assessment of mediation effects (indirect pathways). Mediation is estimated and tested in a single step, with potentially more statistical power than traditional multistep methods. ${ }^{37}$ Finally, GSEM software (e.g., M-Plus ${ }^{38}$ ) can incorporate sample weights and the complex sample survey design (clustering and stratification) into the analysis. This advance permits the appropriate application of GSEM to complex sample survey data including the NHIS.

The GSEM depicted in Figure 1 was fit to the data with the aforementioned additional covariate controls. ${ }^{36}$ The equations for the VI and self-rated health outcomes are logistic regressions, that for the disability latent variable outcome is ordinary linear regression, and that for the mortality outcome is a Cox proportional hazards regression. The disability latent factor is continuous, but the paths linking disability to the variables days in bed and days of restricted-activity are Poisson. The disability latent variable combines these variables while removing the random measurement error from each. All equations are estimated simultaneously by using a weighted maximum-likelihood estimator, ${ }^{39}$ with standard errors that are corrected for all features of the complex sample features of the NHIS. ${ }^{40}$

First, the model was estimated without the mortality outcome, to obtain traditional SEM estimated fit statistics for the model without mortality (model 1)..$^{35,41,42}$ Second, the mortality outcome was added, and estimates were provided from this model (model 2). Third, model 2 was re-estimated, treating the ordinal self-rated health variable as

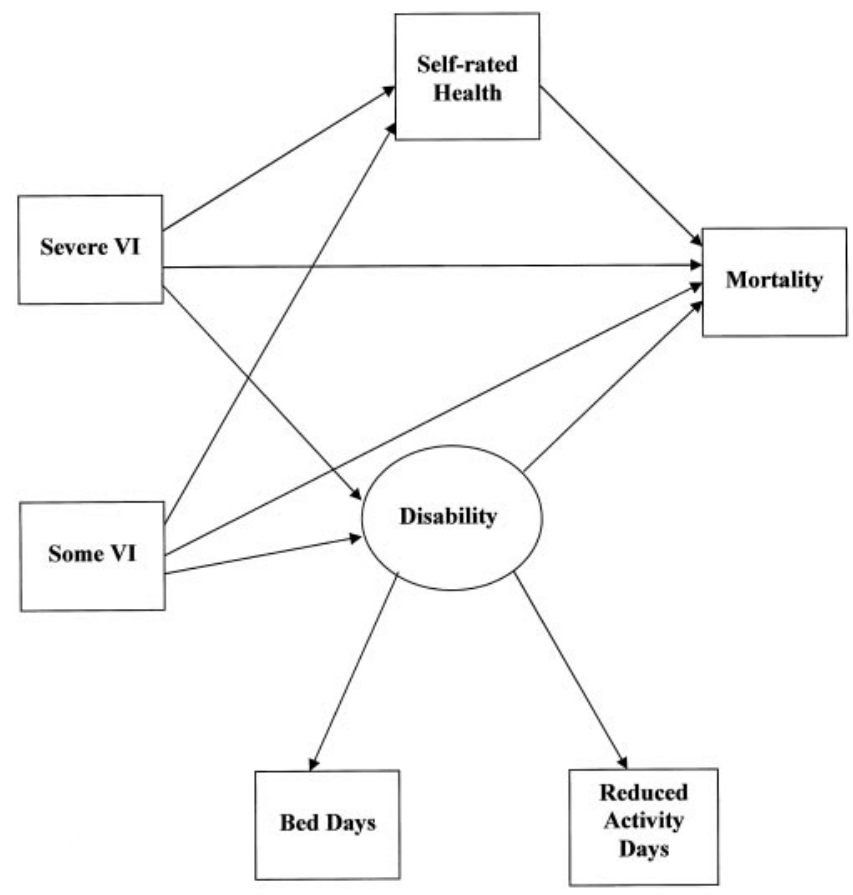

Figure 1. Path model for select portion of the GSEM for the relationship between VI and mortality. All paths are controlled for covariates with the exception of the paths from disability to its indicators.

continuous to calculate indirect effects on mortality through self-rated health. Results from this model were identical with the results in model 2 , in which self-rated health was treated as ordinal with the exception of a slight change in the effects of nonocular conditions on disability and the change from logit to linear parameters for the self-rated health outcome. Finally, the mortality outcome is rescaled from time intervals in days to time intervals in years, to obtain baseline hazards estimates (model 3). Results from model 3 were the same as those from model 2 for all outcomes except mortality. Results from the mortality equations were substantively the same in size and significance of effects.

Indirect or mediation effects are calculated by multiplying the two parameters involved in the mediation relationship. ${ }^{35,43}$ For example, to obtain the effect of VI on mortality through the disability mechanism, the raw coefficients for the effect of VI on disability are multiplied by the effect of disability on mortality. The new parameter is exponentiated to obtain the hazard ratio (HR) for the indirect effect. Total effects are the effects of the independent variable (VI) on mortality through all pathways, including the direct and all mediation pathways after adjustment for model covariates. Total effects are calculated by summing the raw coefficients for the direct effects together with the indirect effects. Standard errors for both indirect and total effects were obtained by using the delta method. ${ }^{44}$

Descriptive and model-based analyses were completed with adjustments for sample weights and design effects (SUDAAN 9.0, 2004 ${ }^{45}$; Research Triangle Institute, Research Triangle Park, NC, and M-Plus $4.21^{38}$ statistical packages, respectively).

\section{Results}

The sample of 135,581 adults represents an estimated 29.3 million adults in the noninstitutionalized U.S. population. There were 17,842 observed deaths in this sample. The average age of this population was 44 years. The population included $47.3 \%$ males, $11.2 \%$ African American, 5.9\% other race, and $82.9 \%$ white. An estimated $64 \%$ of the population was married, $38 \%$ had a high school or equivalent education, and $41 \%$ had more than a high school education. Twenty-two 
TABLE 1. HRs of the Direct Effects on Mortality

\begin{tabular}{lcc}
\hline & HR & 95\% CI \\
\hline Age & 1.08 & $1.08-1.08$ \\
Male & 1.78 & $1.72-1.84$ \\
African American & 1.07 & $1.02-1.13$ \\
Other race/ethnicity & 0.75 & $0.66-0.84$ \\
Married & 0.78 & $0.75-0.80$ \\
High school graduate & 0.98 & $0.94-1.02$ \\
More than high school & 0.83 & $0.79-0.87$ \\
One nonocular condition & 0.95 & $0.88-1.02$ \\
Two+ nonocular conditions & 1.01 & $0.94-1.09$ \\
Some VI & 1.13 & $1.07-1.20$ \\
Severe VI & 1.28 & $1.07-1.53$ \\
Poor self-rated health & 1.31 & $1.29-1.34$ \\
Disability & 1.03 & $1.03-1.04$ \\
\hline
\end{tabular}

percent and $21 \%$ of the population had one and more than one nonocular condition, respectively. Four percent had some VI, and $0.28 \%$ had severe VI or blindness in both eyes. One third of the population (34\%) rated their health as excellent, $29 \%$ as very good, $25 \%$ as good, $9 \%$ as fair, and $4 \%$ as poor. The majority (89\%) had had no restricted activity days in the past 2 weeks, and $94 \%$ had had no bed days in the past 2 weeks.

The SEM model without the mortality linkage (model 1) had an excellent model fit. The comparative fit index (CFI) and Tucker-Lewis index (TLI) are 1.00 and 0.998, respectively, where a value of 1.00 indicates excellent fit. ${ }^{35}$ The root-meansquare-error of approximation (RMSEA) is 0.006 , where 0.00 indicates excellent fit. ${ }^{46,47}$ The $\chi^{2}$ test of model fit is significant, indicating a poor fit $(52.960, d f=8 ; P<0.001)$, where a nonsignificant $\chi^{2}$ is desired. However, with more than 135,000 cases, the power to detect minor departures from the data is high. ${ }^{48}$

Reliability estimates for the disability indicators are obtained from model 1 . Both indicators are very reliable, with estimates of 0.94 and 0.99 for the number of bed days and number of restricted-activity days, respectively.

Tables 1 through 3 present the estimates when the mortality outcome is added to the model (model 2 ). Table 1 gives the direct effects of all variables on mortality. Both some and severe VI significantly affects mortality with HRs 1.13 (95\% CI: 1.07-1.20) and 1.28 (95\% CI: 1.07-1.53), respectively. Note that the direct effects from the GSEM are very similar to the effects one would obtain from a standard, single-equation Cox regression model that includes self-rated health and disability as independent control variables, which are HR 1.14 (95\% CI: 1.07-1.21) and HR 1.30 (95\% CI: 1.09-1.56) for some VI and severe VI, respectively.

It is important to note that both of the mediators for the relationships between VI and mortality (i.e., self-rated health and disability) have a significant positive impact on mortality hazard. A one-unit increase in poorer self-rated health increases the hazard of death by 1.31 (95\% CI: 1.29-1.34). A one-unit increase in disability increases the hazard of death by a factor of 1.03 (95\% CI: 1.03-1.04). The effect of a one-SD unit increase in disability is a HR of 1.23 .

Table 2 presents the indirect effects of VI on mortality through the self-rated health variable and the disability variable, after adjustment for model covariates. The indirect effects are calculated as the product of the two direct effects involved in the mediation relationship. For example, the log-hazard effect of VI on disability multiplied by the log-hazard effect of disability on mortality represents the indirect log-hazard effect of VI on mortality through disability. Table 2 also gives the total effect of VI on mortality, by combining the direct effect and both of the mediation (indirect) effects, where total effects are calculated as the sum of the log-hazard direct and indirect effects.

The indirect effect of VI on mortality through self-rated health increases the hazard by a factor of 1.07 (95\% CI: $1.06-$ 1.08) and severe VI increases the hazard by a factor of 1.17 (95\% CI: 1.13-1.21). The total effects of VI on mortality are the direct effects plus the mediation effects through both self-rated health and disability. The total effects are: HR 1.23 (95\% CI: 1.16-1.31) for some VI and HR 1.54 (95\% CI: 1.28-1.86) for severe VI. The total effects can be compared to the direct effects only, which are relatively smaller and are comparable to what is obtained in a traditional Cox proportional hazards model.

Another way to view the degree to which VI impacts mortality through multiple pathways is to consider the difference in the baseline hazard functions for the three levels of VI. Figure 2A portrays the line graph of the baseline hazard function for a standard Cox proportional hazards model (albeit with a latent variable predictor) controlling for covariates. Figure $2 \mathrm{~B}$ portrays the line graph of the baseline hazard function for the full GSEM model accounting for both the direct and indirect impacts of VI and adjusting for the covariates. The baseline represents the hazard function for a 50-year-old, white, married male in good health, with no nonocular conditions and 1 standard deviation below average disability. Comparison of Figures $2 \mathrm{~A}$ and $2 \mathrm{~B}$ reveals that the impact of VI on all-cause mortality is much greater when the estimated effects of VI operating through the health and disability mediators are considered.

\section{Discussion}

Consistent with previous studies, ${ }^{3,5,22-28}$ we found an association between reported VI and mortality in community-residing adults even after adjustment for sociodemographic covariates, self-rated health, number of nonocular health conditions, and disability. Unlike previous studies, we estimated the indirect effects of VI on mortality risk, which could operate through the impact of VI on self-rated health and on disability. We found the association between VI and mortality risk to be stronger when these indirect pathways were estimated simultaneously using GSEM (Fig. 2). These indirect effects were stronger for self-rated health than for disability, although HRs were significantly elevated for both. Our results demonstrate the utility of moving beyond single-equation HR models to analyses that employ SEM. Use of such techniques is particularly important, given the broad range of mental and physical health indicators associated with VI. SEM could be used widely to examine other important associations with complex pathways, such as the relationship of age-related macular degener-

TABLE 2. HRs of the Indirect Effects and the Total Effect of Reported VI on Mortality

\begin{tabular}{lcc}
\hline & $\begin{array}{c}\text { Hazard } \\
\text { Ratio }\end{array}$ & 95\% CI \\
\hline $\begin{array}{l}\text { Indirect effects through disability } \\
\quad \text { Some VI }\end{array}$ & 1.02 & $1.01-1.02$ \\
$\quad$ Severe VI & 1.03 & $1.01-1.05$ \\
Indirect effects through self-rated health & 1.07 & $1.06-1.08$ \\
$\quad$ Some VI & 1.17 & $1.13-1.21$ \\
$\quad$ Severe VI & & \\
$\quad \begin{array}{l}\text { Total effect through direct and both indirect } \\
\quad \text { pathways }\end{array}$ & 1.23 & $1.16-1.31$ \\
$\quad$ Some VI & 1.54 & $1.28-1.86$ \\
$\quad$ Severe VI & & \\
\hline
\end{tabular}

All effects are adjusted for model covariates. 
TABLE 3. Cumulative ORs of the Direct Effects on Poor Self-Rated Health and Linear Regression of the Direct Effects on Disability

\begin{tabular}{|c|c|c|c|c|}
\hline & \multicolumn{2}{|c|}{ Self-Rated Health Mediator* } & \multicolumn{2}{|c|}{ Disability Mediator† } \\
\hline & OR & $95 \% \mathrm{CI}$ & Ordinary Linear $\boldsymbol{\beta}$ & $95 \% \mathrm{CI}$ \\
\hline Age & 1.02 & $1.02-1.02$ & -0.03 & $-0.03--0.03$ \\
\hline Male & 0.78 & $0.77-0.80$ & -0.67 & $-0.74--0.60$ \\
\hline African American & 1.92 & $1.83-2.02$ & 0.46 & $0.35-0.58$ \\
\hline Other race/ethnicity & 1.53 & $1.43-1.64$ & 0.33 & $0.16-0.50$ \\
\hline Married & 1.00 & $0.97-1.03$ & -0.11 & $-0.18--0.04$ \\
\hline High school graduate & 0.54 & $0.52-0.56$ & -0.35 & $-0.44--0.26$ \\
\hline More than high school & 0.30 & $0.29-0.31$ & -0.34 & $-0.43--0.24$ \\
\hline One nonocular condition & 2.09 & $2.03-2.15$ & 6.69 & $6.53-6.84$ \\
\hline Two + nonocular conditions & 5.76 & $5.54-5.98$ & 8.24 & $8.07-8.41$ \\
\hline Some VI & 1.60 & $1.51-1.69$ & 0.46 & $0.33-0.60$ \\
\hline Severe VI & 2.96 & $2.32-3.77$ & 0.98 & $0.45-1.52$ \\
\hline
\end{tabular}

* Model $r^{2}=0.760$.

† Model $r^{2}=0.716$; the standard deviation of the disability mediator is 5.98 .

ation with risk of cardiovascular disease and ultimately causespecific mortality outcomes such as myocardial infarction.

GSEM also allows for the measurement of constructs by using latent variables (or factors). Latent variables lead to testable hypotheses that help in the understanding of associations between VI and mortality. For example, the concept of frailty, loosely defined as aging-associated declines in organ systems, is associated with an increased risk of mortality. ${ }^{49,50}$ Presently, no standardized measure of frailty exists that is typically operationalized as an index including components such as low grip strength, low levels of physical activity, and low peak expiratory flow. ${ }^{49,50}$ Some investigators also include VI levels in the frailty index. These indexes have also been shown to be predictive of mortality. ${ }^{51,52}$ SEM could be used to identify a common set of measures that load optimally on a frailty construct (which could be estimated net of random measurement error) and then determine the extent to which frailty is predictive of mortality. SEM therefore, can be used by investigators to test specifically whether VI should be considered a key frailty indicator or whether VI influences mortality risk through a pathway independent of frailty.

The inclusion of frailty in mortality models that include assessment of other ocular conditions such as cataract, glaucoma, and age-related macular degeneration and mortality risk may provide a theoretically plausible explanation for these previously documented associations. Furthermore, SEM provides a very flexible analytic platform to examine simultaneously other proposed hypotheses that may account for associations between ocular diseases and mortality risk, such as the cardiovascular risk factor hypothesis, which posits that risk factors common to both cardiovascular mortality risk and the development of ocular conditions (e.g., smoking) may partially explain associations between ocular disease and increased mortality risk. ${ }^{53-55}$ As demonstrated in the present analysis SEM provides a flexible analytic approach to the testing of potential mediation effects such as between smoking, the development of select ocular diseases, and mortality risk.

The NHIS lacks routine assessment of important risk factors, such as depression, as well as a comprehensive assessment of smoking status, which would be an important covariate to include in any mortality analysis. Current smoking status was assessed in a subset of NHIS participants in years 1987, 1988, and 1990 to $1994(n=40,211) .^{56}$ We reran our final SEM models in this subset and found only modest reductions in our HR estimates for VI when compared with the results based on our full sample. The total HR estimate for all pathways for some VI is reduced from 1.23 (Table 2) to 1.16 (95\% CI: 1.05-1.28) when smoking is accounted for in the model. Corresponding
HR estimates for severe VI are 1.54 and 1.48 (95\% CI: $1.15-$ 1.89).

Another potential limitation of the NHIS is that proxy information was gathered for household members who were not present for the interview. In this sample, $37 \%$ of the respondents were proxy reporters. We reran the full GSEM model with proxy as a covariate, and results for all the VI effects were nearly identical with those reported for this study. We also evaluated results for the proxy and self-report populations separately and found that most results were very similar. There are no statistically significant differences in the effects of VI on self-rated health and disability for the two types of reporters. However, there is a significant difference in the direct effect of severe VI on mortality for self-reporters versus proxy-reporters $(z=2.38, P=0.017)$ where the effect is stronger in the case of proxy reporting, perhaps because self-reporters are somewhat more likely to report some VI (OR: 1.14; 95\% CI: $1.06-$ 1.23) and less likely to report severe VI (OR: $0.62 ; 95 \% \mathrm{CI}$ : $0.47-0.83$ ). The direct effect of some VI on mortality is similar for both types of reporters. Finally, the NHIS is a cross-sectional survey with mortality linkage. No repeat household interviews were completed that would have permitted assessment of change in VI and mortality risk.

Inherent in any self-reported health survey is the presence of misclassification of VI status. Data on the validity of the two VI questions used in the NHIS are not available; however, validation studies of other global self-reported VI measures correlate modestly with clinical indicators of VI. For example, overall VI assessed by either one or two items within the National Eye Institute Visual Function Questionnaire (NEI-VFQ) correlates significantly with clinically assessed visual acuity (range of correlations, $0.65-0.68) .{ }^{57,58}$

Despite these limitations, the NHIS has several important strengths, including a large sample size representative of the U.S. noninstitutionalized household population, excellent household response rates (95\%-98\%), and a mortality linkage that is $96 \%$ complete, resulting in the identification of more than 17,842 deaths in our analysis. The large sample size permitted the identification of more than 385 adults with severe VI-a sample size that is impossible to obtain in smaller population-based clinical ocular epidemiology studies.

To summarize, we found that reported VI was predictive of an increased risk of mortality even after control for sociodemographic measures, chronic conditions, self-reported health, and disability. Visual impairment had both direct and indirect effects on mortality, operating in part through influence on self-rated health and disability. Investigators interested in asso- 


\section{A Baseline Hazards Function for Cox Proportional Hazard Model}

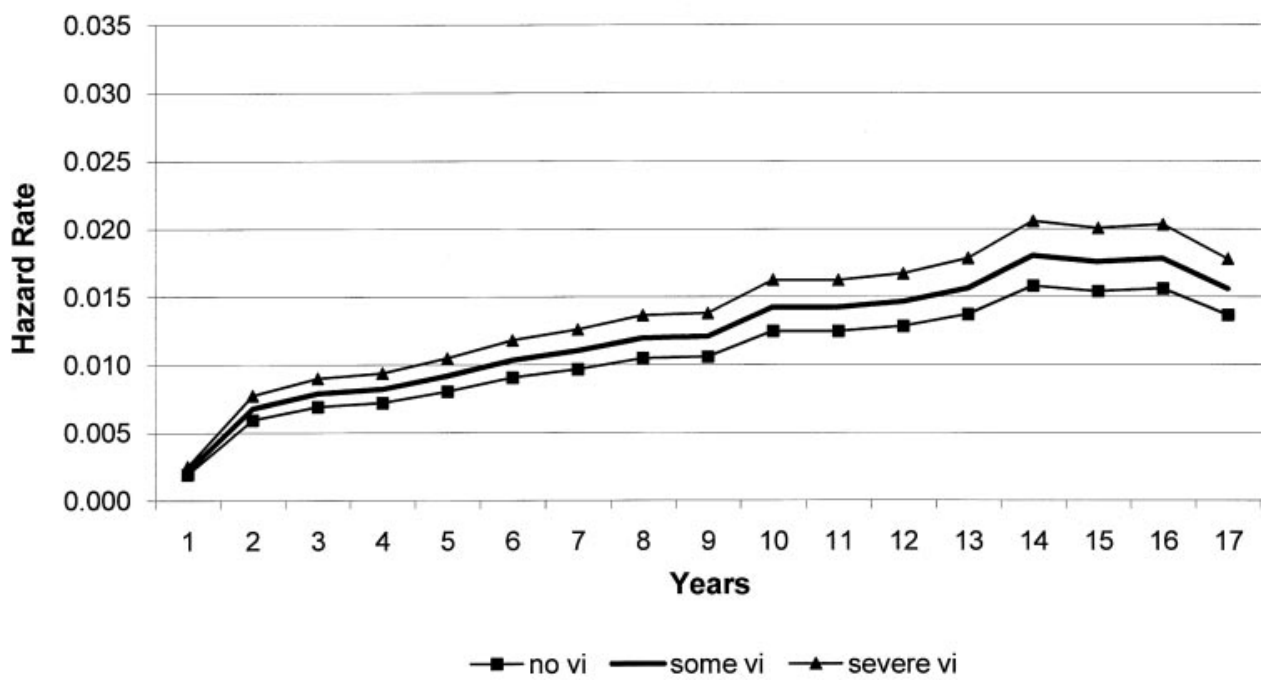

B

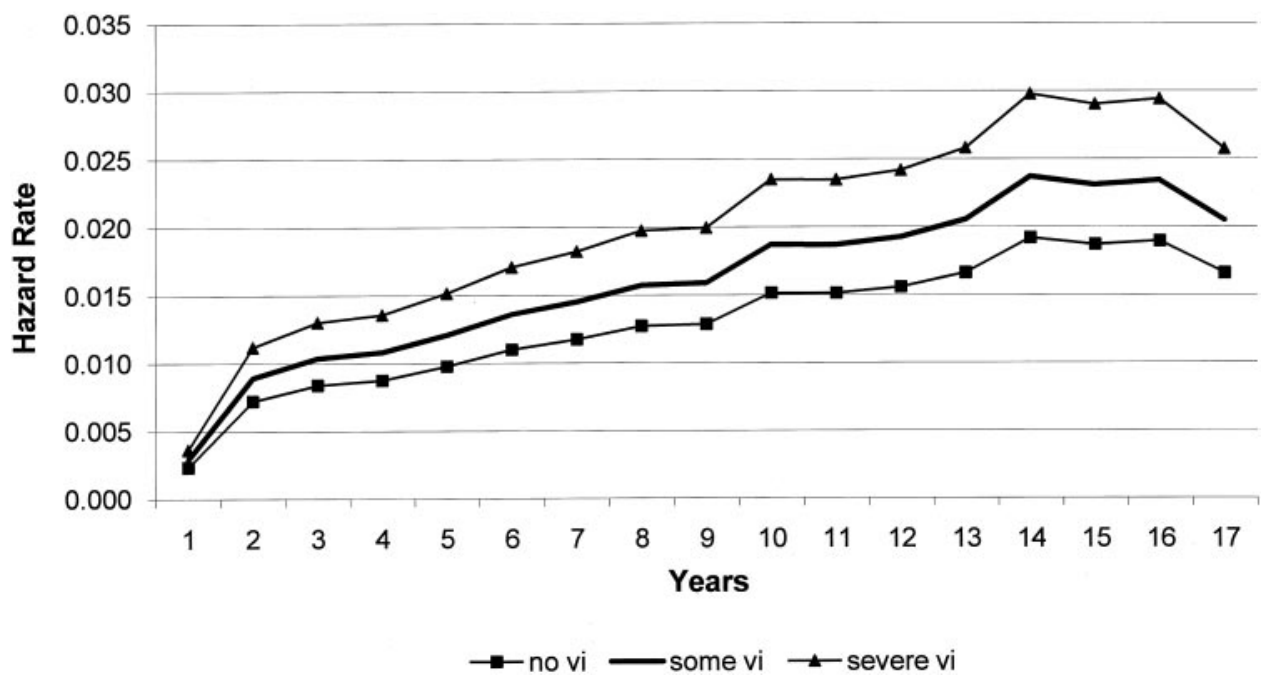

FiguRE 2. Baseline hazards function for three VI levels from a single equation Cox proportional hazards model (A) and from the full SEM (B) for a 50-year-old, white, married male in good health with no nonocular conditions and one standard deviation below average disability. The full SEM accounts for both the direct and indirect impacts of VI and the covariates. The impact of VI on all-cause mortality is much greater when estimated indirect effects of VI operating through the health and disability mediators are considered. ciations between VI and mortality are encouraged to test their models by using GSEM, which will permit a more complete examination of pathways through which VI increases mortality risk.

\section{References}

1. Verbrugge LM, Lepkowski JM, Imanaka Y. Comorbidity and its impact on disability. Milbank Q. 1989;67(3-4):450- 484.

2. Chia EM, Wang JJ, Rochtchina E, Smith W, Cumming RR, Mitchell P. Impact of bilateral visual impairment on health-related quality of life: The Blue Mountains Eye Study. Invest Ophthalmol Vis Sci. 2004; $45(1): 71-76$.

3. Whitson HE, Cousins SW, Burchett BM, Hybels CF, Pieper CF, Cohen HJ. The combined effect of visual impairment and cognitive impairment on disability in older people. J Am Geriatr Soc. 2007; 55(6):885-891.

4. Wallhagen MI, Strawbridge WJ, Shema SJ, Kurata J, Kaplan GA. Comparative impact of hearing and vision impairment on subsequent functioning. J Am Geriatr Soc. 2001;49(8):1086-1092.

5. Jacobs JM, Hammerman-Rozenberg R, Maaravi Y, Cohen A, Stessman J. The impact of visual impairment on health, function and mortality. Aging Clin Exp Res. 2005;17(4):281-286.
6. Rudberg MA, Furner SE, Dunn JE, Cassel CK. The relationship of visual and hearing impairments to disability: an analysis using the longitudinal study of aging. J Gerontol. 1993;48(6):M261-M265.

7. Swanson MW, McGwin G. Visual impairment and functional status from the 1995 national health interview survey on disability. $O p b$ thalmic Epidemiol. 2004;11(3):227-239.

8. West SK, Munoz B, Rubin GS, et al. Function and visual impairment in a population-based study of older adults. The See ProjectSalisbury Eye Evaluation. Invest Ophthalmol Vis Sci. 1997;38(1): 72-82.

9. Carabellese C, Appollonio I, Rozzini R, et al. Sensory impairment and quality of life in a community elderly population. J Am Geriatr Soc. 1993;41(4):401- 407 .

10. Wahl HW, Tesch-Romer H, Rott C. Vision and cognitive functioning in old age. In: Silverstone B, Lang MA, Rosenthal MA, Faye EE, eds. The Lighthouse Handbook on Vision Impairment and Vision Rehabilitation. New York: Oxford University Press; 2000: 431-439.

11. Horowitz A, Reinhardt JP. Mental health issues in depression: research in depression, disability, and rehabilitation. In: Silverstone B, Lang MA, Rosenthal MA, Faye EE, eds. The Lighthouse Handbook on Vision Impairment and Vision Rebabilitation. New York: Oxford University Press; 2000:1089-1109. 
12. Lee DJ, Gomez-Marin O, Lam BL. Current depression, life history of depression, and visual acuity in Hispanic adults. J Visual Impair Blind. 2000;94:86-96.

13. Varma R, Wu J, Chong K, Azen SP, Hays RD. Impact of severity and bilaterality of visual impairment on health-related quality of life. Ophthalmology. 2006;113(10):1846-1853.

14. Lee PP, Smith JP, Kington RS. The associations between self-rated vision and hearing and functional status in middle age. Ophthalmology. 1999;106(2):401-405.

15. Salive ME, Guralnik J, Glynn RJ, Christen W, Wallace RB, Ostfeld AM. Association of visual impairment with mobility and physical function. J Am Geriatr Soc. 1994;42(3):287-292.

16. Jette AM, Branch LG. Impairment and disability in the aged. J Chronic Dis. 1985;38(1):59-65.

17. Ivers RQ, Mitchell $P$, Cumming RG. Sensory impairment and driving: The Blue Mountains Eye Study. Am J Public Health. 1999;89(1):85-87.

18. Owsley $\mathrm{C}$, Ball $\mathrm{K}$, McGwin $\mathrm{G} \mathrm{Jr}$, et al. Visual processing impairment and risk of motor vehicle crash among older adults. JAMA. 1998; 279(14):1083-1088.

19. Cummings SR, Nevitt MC, Browner WS, et al. Risk factors for hip fracture in white women: study of osteoporotic fractures research group. N Engl J Med. 1995;332(12):767-773.

20. Klein BE, Klein R, Lee KE, Cruickshanks KJ. Performance-based and self-assessed measures of visual function as related to history of falls, hip fractures, and measured gait time. The Beaver Dam Eye Study. Ophthalmology. 1998;105(1):160-164.

21. Wang JJ, Mitchell P, Smith W. Vision and low self-rated health: The Blue Mountains Eye Study. Invest Ophthalmol Vis Sci. 2000;41(1): 49-54.

22. Appollonio I, Carabellese C, Magni E, Frattola L, Trabucchi M Sensory impairments and mortality in an elderly community population: a six-year follow-up study. Age Ageing. 1995;24(1): $30-36$.

23. Reuben DB, Mui S, Damesyn M, Moore AA, Greendale GA. The prognostic value of sensory impairment in older persons. $J \mathrm{Am}$ Geriatr Soc. 1999;47(8):930-935.

24. Wang JJ, Mitchell P, Simpson JM, Cumming RG, Smith W. Visual impairment, age-related cataract, and mortality. Arch Ophthalmol. 2001;119(8): $1186-1190$

25. Thompson JR, Gibson JM, Jagger C. The association between visual impairment and mortality in elderly people. Age Ageing. 1989; 18(2):83-88.

26. McCarty CA, Nanjan MB, Taylor HR. Vision impairment predicts 5 year mortality. Br J Ophthalmol. 2001;85(3):322-326.

27. Lee DJ, Gomez-Marin O, Lam BL, Zheng DD. Visual acuity impairment and mortality in us adults. Arch Ophthalmol. 2002;120(11): $1544-1550$

28. Cacciatore F, Abete P, Maggi S, et al. Disability and 6-year mortality in elderly population: role of visual impairment. Aging Clin Exp Res. 2004;16(5):382-388.

29. Lee DJ, Gomez-Marin O, Lam BL, Zheng DD. Visual impairment and unintentional injury mortality: The National Health Interview Survey 1986-1994. Am J Ophthalmol. 2003;136(6):1152-1154.

30. Podgor MJ, Cassel GH, Kannel WB. Lens changes and survival in a population-based study. $N$ Engl J Med. 1985;313(23):1438-1444.

31. West SK, Munoz B, Istre $J$, et al. Mixed lens opacities and subsequent mortality. Arch Ophthalmol. 2000;118(3):393-397.

32. Lee DJ, Gomez-Marin O, Lam BL, Zheng DD, Caban A. Visual impairment and morbidity in community-residing adults: The National Health Interview Survey 1986-1996. Ophthalmic Epidemiol. 2005;12(1):13-17.

33. Benjamins MR, Hummer RA, Eberstein IW, Nam CB. Self-reported health and adult mortality risk: an analysis of cause-specific mortality. Soc Sci Med. 2004;59(6):1297-1306.

34. Idler EL, Benyamini Y. Self-rated health and mortality: a review of twenty-seven community studies. J Health Soc Behav. 1997;38(1): 21-37.
35. Bollen K. Structural Equations with Latent Variables. New York: Wiley; 1989.

36. Skrondal A, Rabe-Hesketh S. Generalized Latent Variable Modeling: Multilevel, Longitudinal and Structural Equation Models. Boca Raton, FL: Chapman \& Hall/CRC Press; 2004.

37. MacKinnon DP, Lockwood CM, Hoffman JM, West SG, Sheets V. A comparison of methods to test mediation and other intervening variable effects. Psychol Methods. 2002;7(1):83-104.

38. Muthén LK, Muthén BO. M-Plus User's Guide. Los Angeles: Muthén \& Muthén; 1998-2007.

39. Skinner CJ. Domain means, regression and multivariate analysis. In: Skinner CJ, Holt D, Smith TMF, eds. Analysis of Complex Surveys. New York: Wiley; 1989:59-87.

40. Binder D. On the variance of asymptotically normal estimators from complex surveys. Int Stat Rev. 1983;51:279-292.

41. Browne MW. Covariance structures. In: Hawkins DM, ed. Topics in Multivariate Analysis. Cambridge: Cambridge University Press; 1982:72-141.

42. Browne MW. Asymptotically distribution-free methods for the analysis of covariance structures. Br J Math Stat Psychol. 1984;37: 62-83.

43. Bollen KA. Total, direct, and indirect effects in structural equation models. In: Clogg C, ed. Sociological Methodology 1987. Washington, DC: American Sociological Association; 1987:37-69.

44. Greene WH. Econometric Analysis. Englewood Cliffs, NJ: Prentice Hall; 2003.

45. RTI. Sudaan Language Manual, Release 9.0. Research Triangle Park, NC: Research Triangle Institute; 2004.

46. Steiger JH, Lind JM. Statistically Based Tests for the Number of Common Factors. Paper presented at the Annual Meeting of the Psychometric Society, Iowa City, IA; 1980.

47. Browne MW, Cudeck R. Alternative ways of assessing model fit. In: Bollen K, Long JS, eds. Testing Structural Equation Models. Newbury Park, CA: Sage Publications; 1993:136-162.

48. Bentler PM, Bonett DG. Significance tests and goodness of fit in the analysis of covariance structures. Psychol Bull. 1980;88(3):588606.

49. Rockwood K, Song X, MacKnight C, et al. A global clinical measure of fitness and frailty in elderly people. CMAJ. 2005;173(5):489495.

50. Fried LP, Tangen CM, Walston J, et al. Frailty in older adults: evidence for a phenotype. J Gerontol A Biol Sci Med Sci. 2001; 56(3):M146-M156.

51. Klein BE, Klein R, Knudtson MD, Lee KE. Frailty, morbidity and survival. Arch Gerontol Geriatr. 2005;41(2):141-149.

52. Puts MT, Lips P, Deeg DJ. Sex differences in the risk of frailty for mortality independent of disability and chronic diseases. $\mathrm{J} \mathrm{Am}$ Geriatr Soc. 2005;53(1):40 - 47.

53. Lee DJ, Gómez-Marín O, Lam BL, Zheng DD. Glaucoma and survival: The national health interview survey 1986-1994. Ophthalmology. 2003;110(8):1476-1483.

54. Borger PH, van Leeuwen R, Hulsman CA, et al. Is there a direct association between age-related eye diseases and mortality?-The Rotterdam Study. Ophthalmology. 2003;110(7):1292-1296.

55. Hirai FE, Moss SE, Knudtson MD, Klein BE, Klein R. Retinopathy and survival in a population without diabetes: The Beaver Dam Eye Study. Am J Epidemiol. 2007;166(6):724-730.

56. Lee DJ, LeBlanc W, Fleming LE, Gomez-Marin O, Pitman T. Trends in US smoking rates in occupational groups: The National Health Interview Survey 1987-1994. J Occup Environ Med. 2004;46(6): 538-548.

57. Mangione CM, Lee PP, Pitts J, Gutiérrez P, Berry S, Hays RD. Psychometric properties of the national eye institute visual function questionnaire (NEI-VFQ). NEI-VFQ field test investigators. Arch Ophthalmol. 1998;116(11):1496-1504.

58. Mangione CM, Lee PP, Gutiérrez PR, Spritzer K, Berry S, Hays RD. Development of the 25-item national eye institute visual function questionnaire. Arch Ophthalmol. 2001;119(7):1050-1058. 